\section{Degradabilidade de farinhas de carne e osso, e de soja, pela técnica dos sacos de náilon in situ, em caprinos e bovinos}

\author{
Soybeans and meat-bone meal degradabilities, through nylon bags \\ in situ technique, in dairy heifers and goats
}

\author{
José Ricardo Soares Telles de SOUZA'; Carlos de Sousa LUCCI² I Laércio MELOTTI
}

CORRESPONDENCE TO Carlos de Sousa LuCci Departamento de Nutrição e Produção Animal Faculdade de Medicina Veterinária e Zootecnia da USP Av. Duque de Caxias Norte, 255 - Caixa Postal 23 Caixa Postal 23 $13630-970$ - Pirassununga - SP Brasil e-mail: cslucci@usp.br 1 - Faculdade Estadual de São Luis do Maranhão - MA
2 - Departamento de Nutriçăo e Produção Animal

\title{
RESUMO
}

Caprinos e bovinos foram utilizados num delineamento change over $3 \times 3$, para avaliar a degradabilidade dos tratamentos: A) farinha de carne e osso com $50 \%$ de proteína bruta (FCO 50); B) farinha de carne e osso com $40 \%$ de proteína bruta (FCO 40) e C) farelo de soja (FS) pela técnica dos sacos de náilon in situ. Cana-de-açúcar foi o único volumoso ofertado. As taxas de degradabilidade da MS (matéria seca) e PB (proteína bruta) foram semelhantes entre caprinos e bovinos, em todos os tratamentos. Os valores de degradabilidade da FCO-40 e da FCO-50 foram semelhantes, porém menores ( $p<0,01)$ do que o FS a partir de 1,5 hora de incubação. A degradabilidade efetiva da MS foi de 77,4\% para o FS; $39,0 \%$ para a FCO-40 e $39,1 \%$ para a FCO-50. Nos tempos 1,5 h, 3 h, 6 h e 12 h a FCO-50 teve a PB menos degradada que a FCO-40. O FS apresentou sua PB mais degradada dos que as FCO, somente nos tempos de $12 \mathrm{~h}$ e $48 \mathrm{~h}$ de incubação ( $\mathrm{p}<0,05$ ). A degradabilidade efetiva da PB foi de $72,4 \%$ para o FS; $54,4 \%$ para a FCO-40 e $49,8 \%$ para a FCO-50. O experimento permitiu concluir que as FCO podem prover maiores quantidades de PB para os intestinos, em relação ao FS, após 12 horas de incubação.

UNITERMOS: Digestibilidade; Caprinos; Bovinos; Farelo de soja; Farinha de carne e osso.

\section{INTRODUÇÃO}

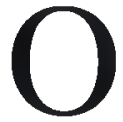
s sistemas modernos de alimentação dão enfase à quantificação da proteína degradada no rúmen $\left(\mathrm{ARC}^{2}\right.$ (1980); $\operatorname{NRC}^{17}$ (1989); $\left.\operatorname{AFRC}^{\prime}(1992)\right)$, considerando, em uma nova abordagem, que os requerimentos de nitrogênio $(N)$ de aminoácidos são a soma do nitrogênio degradável (NDR) e não degradável (NNDR) no rúmen.

No Brasil, a farinha de carne e osso ( $\mathrm{FCO}$ ) vem ganhando importância na alimentação de ruminantes pelo seu uso crescente como lonte de NNDR nos animais produtores de leite, tanto nos rebanhos bovinos como caprinos. Esse produto tem sua fração proteica considerada de baixa degradabilidade, conforme verificado in vitm (Broderick et al. ${ }^{4}$. 1988) e in vivo (Zinn et al. ${ }^{29}, 1981$ ). Além disso, sua proteína pode apresentar níveis baixos de nitrogênio insolúvel em detergente ácido, indicando ser bastante digestível ao nível de intestinos.

O CNPSA (1985) relacionou três tipos de FCO com teores de proteína bruta (PB) de $33 \%, 40 \%$ e $50 \%$, analisadas segundo as metodologias descritas pela $\mathrm{AOAC}^{3}(1980)$. Piecznski et al. ${ }^{20}(1986)$, trabalhando com vários tipos de FCO, encontraram valores que variavam de $51,4 \%$ a $70,6 \%$ de $\mathrm{PB}$ e $6,2 \%$ a $22,3 \%$ de minerais (MM); Just et al." (1983), analisando 132 amostras de FCO, registraram $47,2 \%$ a $65,0 \%$ de PB, e $22,0 \%$ a $38,5 \%$ de MM. A Secretaria Nacional de Defesa Agropecuária ${ }^{23}$ (1988) classificou a FCO em quatro lipos: com 40\% PB, 45\% PB, 50\% PB e 55\% PB e com um mínimo de $3,8 \%$ de fósforo $(P)$.

$\mathrm{O}$ valor de FCO está em função de qualidade de matériaprima, processamento, quantidade e disponibilidade de aminoácidos essenciais, contaminação bacteriana, nível de minerais, particularmente cálcio e fósforo, e da presença de resíduos (Valle ${ }^{2 \hbar}, 1975$; Donzele; Lopes? ${ }^{7}$ 1988).

A maioria dos subprodutos de origem animal, além de ser fontes de PB de boa qualidade, serve como importante fonte de minerais, em face da razoável composição em fósforo, considerado $100 \%$ disponível (Scott et al. ${ }^{22}, 1982$ ). Lu et al. ${ }^{14}$ (1990) encontraram retenção de cálcio e fósforo ligeiramente maior quando cabras em lactação eram alimentadas com dieta à base de FCO do que à base de farelo de soja (FS). Os mesmos autores registraram melhor aproveitamento de fibra em detergente neutro (FDN) em cabritos alimentados com dieta contendo FCO do que naquela contendo FS. Ainda esses autores, trabalhando com cabras em lactação, não encontraram diferenças no consumo ou nos componentes ruminais, $\mathrm{pH}$, nitrogênio amoniacal e ácidos graxos voláteis, como também não observaram diferenças em componentes sanguíneos e na produção e composição do leite ao compararem FCO e FS como ingredientes das dietas. Lu et al. ${ }^{15}$ (1988), trabalhando com cabras recebendo rações em que $50 \%$ da $\mathrm{PB}$ era à base de $\mathrm{FS}$, ou $\mathrm{FCO}+$ uréia ou FCO, encontraram consumo de matéria seca (MS) de 2,$40 ; 2,59$ e $2,56 \mathrm{~kg} /$ dia e produção de leite de $2,50 \mathrm{~kg} ; 2,66 \mathrm{~kg}$ e $2,65 \mathrm{~kg} /$ dia e $\mathrm{N}$ amoniacal no líquido ruminal ( $\mathrm{mg} / \mathrm{dl}$ ) 12,9;21,4 e 12,2 respectivamente.

Kirpatrick; Kennelly'2(1987), assumindo taxa de passagem dos alimentos no rúmen igual a $0,05 / \mathrm{h}$, calcularam a degradabilidade efetiva da MS da FCO em novilhas alimentadas com dieta contendo $16,5 \%$ de $\mathrm{PB}$, como igual a $39 \%$ e a degradabilidade efetiva da $\mathrm{PB}$, como $45,9 \%$. Loerch et al. ${ }^{13}$ ( 1983 b) encontraram, em bovinos, taxa de desaparecimento do $\mathrm{N}$ da FCO igual a $50,7 \%$ através 
da técnica de sacos de náilon in situ. Broderick et al. ${ }^{4}$ (1988), trabalhando FCO com a técnica dos sacos de náilon in situ e supondo taxas de passagem (r) de 0,02; 0,05 e 0,08/hora, acusaram valores de $67 \%, 55 \%$ e $50 \%$ de degradabilidade efetiva da PB, para aquelas taxas de pesagem.

Já Orskov et al. ${ }^{19}(1979)$, citados por Orskov ${ }^{18}$ (1982), registraram que a degradabilidade efetiva da PB da FCO diminuiu de $52,1 \%$ para $41,2 \%$ quando as taxas de passagem aumentaram de 0,02 para $0,08 / \mathrm{h}$, e Vilela et $a l .{ }^{27}(1994)$, estudando os efeitos de diferentes rações, com dois níveis de concentrados (10\% e $40 \%$ de MS) e duas formas de volumoso (capim-elefante fresco ou ensilado) sobre a degradabilidade da FCO, obtiveram taxas de degradabilidade de $22,3 \%$ a $25,9 \%$ para MS e $50,1 \%$ a $55,0 \%$ para $\mathrm{PB}$, concluindo que as rações não influenciaram os resultados.

No que tange à $\mathrm{PB}$ da $\mathrm{FCO}$, o $\mathrm{ARC}^{2}(1980)$ registra entre $31 \%$ e $50 \%$ de degradabilidade; o $\operatorname{NRC}^{17}$ (1989) $51 \%$ e Zinn et al. ${ }^{29}$ (1981) $30 \%$ (quando $4 \mathrm{~kg} /$ dia dessa fonte proteica era ofertada a bovinos); Vogel et $_{\text {al. }}{ }^{28}$ (1988) citam 44\%. Valadares Filho et al. ${ }^{25}$ (1990) encontraram $20 \%$ a $32 \%$ e $34 \%$ a $41 \%$ respectivamente para degradabilidade efetiva da MS e do $\mathrm{N}$ de diferentes $\mathrm{FCO}$, em vacas produzindo $8,4 \mathrm{~kg} /$ dia, consumindo $12,2 \mathrm{~kg}$ de $\mathrm{MS}$, considerando taxa de passagem de $0,05 / \mathrm{h}$. Rooke ${ }^{21}$ (1985) determinou o valor nutritivo de resíduos de FCO obtido após incubação ruminal, em bovinos, por $24 \mathrm{~h}$; esses resíduos apresentaram conteúdo de $\mathrm{N}$ e matéria orgânica significativamente reduzida.

Quanto à $\mathrm{PB}$ do farelo de soja (FS), o $\mathrm{ARC}^{2}$ (1980) apresenta degradabilidade entre 0,51 e 0,$70 ;$ o $\operatorname{NRC}^{16}$ (1981), em 39 determinações, encontrou média de 65\%; Vogel et al. ${ }^{28}$ (1988), trabalhando com novilhos, encontraram degradabilidade igual a $62,5 \%$. Thomas et al. ${ }^{24}$ (1988), avaliando o efeito da taxa de desaparecimento da MS do FS comercial, contido em sacos de náilon incubados no rúmen, encontraram valor de 0,021/h. Goh; Hong ${ }^{8}$ (1993), tratando o FS pelo calor, e utilizando diversas temperaturas e tempos de aplicação de valor, verificaram uma redução da degradabilidade ruminal $(\mathrm{p}<0,01)$ quando comparado com o FS não tratado. A degradabilidade da PB (considerando taxa de passagem igual a $0,05 / \mathrm{h}$ ) para os tratamentos com aplicação de calor ficou entre $44,03 \%$ e $52,91 \%$, e para o FS não aquecido foi $75,77 \%$. Kirpatrick; Kennelly ${ }^{12}$ ( 1987) determinaram o desaparecimento efetivo da MS do FS em novilhas alimentadas com dietas contendo $16,5 \%$ de $\mathrm{PB}$ e $19,5 \%$ de $\mathrm{PB}$, assumindo taxa de passagem igual a $0,05 / \mathrm{h}$, como igual a $66,6 \%$ e $69,4 \%$ e da PB de $60,2 \%$ e $64,4 \%$ respectivamente. Loerch et al. ${ }^{13}$ (1983b) encontraram, em bovinos, taxa de desaparecimento do $\mathrm{N}$ do FS de 71,3\% a partir de $12 \mathrm{~h}$ de incubação. Broderick et al. ${ }^{4}$ (1988), com taxas de passagem (r) de
$0,02,0,05$ e $0,08 / \mathrm{h}$, obtiveram para o FS valores de 80,$0 ; 63,0 \%$ e 53\% de degradabilidade efetiva da PB.

Este trabalho teve como objetivo estimar a degradabilidade proteica de dois tipos de FCO com $40 \%$ e $50 \%$ PB, e do farelo de soja (FS) com $46,75 \%$ de PB. além de comparar os dados obtidos em caprinos e bovinos.

\section{MATERIAL E MÉTODO}

O ensaio de degradabilidade foi desenvolvido com a técnica dos sacos de náilon in situ em caprinos e bovinos fistulados, na Faculdade de Medicina Veterinária e Zootecnia da Universidade de São Paulo, Campus Administrativo de Pirassununga.

Foram utilizadas 6 novilhas mestiças com $350 \mathrm{~kg}$ de peso médio e 3 cabras sem raça definida com $40 \mathrm{~kg}$ de peso médio, para comparar 3 tratamentos: A- farinha de carne e osso 50\% PB (FCO50); B-farinha de carne e osso $40 \%$ PB (FCO-40) e C-farelo de soja (FS).

Mistura concentrada única foi fornecida para todos os tratamentos, contendo como fontes proteicas FCO $40 \%$, FCO $50 \%$ e FS, como fonte energética, milho. Como volumoso, foi ministrada cana-de-açúcar. Os concentrados foram fornecidos em duas refeições diárias, às $9 \mathrm{~h}$ e às $15 \mathrm{~h}$ para bovinos e caprinos. A cana-deaçúcar foi fornecida às $9 \mathrm{~h}$ e às $15 \mathrm{~h}$ para bovinos e somente às $9 \mathrm{~h}$ para caprinos. Em qualquer dos casos, as sobras eram constituídas apenas por cana-de-açúcar.

O experimento foi executado de maio a junho de 1994; o delineamento estatístico foi o do tipo change over (Cochran; Cox ${ }^{6}$, 1957) com 4 grupos de animais, 2 com a espécie caprina e 2 com a bovina. Com os caprinos, o segundo grupo foi formado por repetição do primeiro, em outro tempo. As médias foram comparadas pelo teste de Tukey e o nível de significância considerado foi de $5 \%$.

Foi controlada a ingestão de alimentos que era limitada a 2 $\mathrm{kg}$ de MS por $100 \mathrm{~kg}$ de peso vivo. Os sacos de náilon, nos quais foram colocadas isoladamente amostras de FCO-40, FCO-50 e FS, mediam $7 \mathrm{~cm} \times 16 \mathrm{~cm}$, com porosidade aproximada de $40 \times 70$ micras. Todas as amostras foram pesadas com exatidão, próximas a 5 gramas. Os tempos de incubação foram: $0 \mathrm{~h}, 1,5 \mathrm{~h}, 3 \mathrm{~h}, 6 \mathrm{~h}, 12 \mathrm{~h}$, $24 \mathrm{~h}$ e $48 \mathrm{~h}$, sendo colocados todos os sacos ao mesmo tempo e retirados conforme os períodos de incubação desejados. Foram determinadas as degradabilidades da MS e PB; a curva de desaparecimento das amostras foi analisada segundo Orskov; McDonald ${ }^{14}$ (1979), a degradabilidade efetiva, conforme AFRC' (1992), e o volume ruminal e taxa de renovação, através do marcador de fase líquida (o polietilenoglicol - PEG).

Tabela 1

Composição químico-bromatológica dos ingredientes da ração, em porcentagem, com base na matéria seca.

\begin{tabular}{|c|c|c|c|c|c|c|}
\hline INGREDIENTE & MS & PB & EE & MM & $\mathrm{Ca}$ & $\mathbf{P}$ \\
\hline Farinha de carne e osso 40 & 93,50 & 39,16 & 14,50 & 38,00 & 14,33 & 5,72 \\
\hline Farinha de carne e osso 50 & 94,50 & 49,80 & 14,00 & 30,00 & 12,66 & 4,83 \\
\hline Milho (fubá)" & 87,45 & 8,00 & 3,84 & 1,18 & 0,04 & 0,26 \\
\hline Cana-de-açúcar* & 23,20 & 1,00 & 0,80 & 5,80 & 0,21 & 0,10 \\
\hline Concentrado & 85,15 & 34,99 & 3,21 & 5,77 & 0,84 & 0,65 \\
\hline
\end{tabular}

" valores estimados 
SOUYA, J.R.S.T.: LUCCI. C.S ; MEI OTTI, L. Degradahilidade de farinhàs de carne e osso, e de soja, pela técnica dos sacos de náilon in sizu, cm caprinos e hovinos

Braz. J. vet. Kes. anim. Sci., São Paulo, v. 34 , n. 6, p. $358-363.1 \% 47$

Tabela 2

Porcentagens de degradabilidade da matéria seca (MS) da FCO-40, FCO-50 e FS na espécie caprina e na bovina, nos diferentes tempos de incubação ruminal. Degradabilidade efetiva $(p)$ com $r=0,04$.

\begin{tabular}{cccccccccc}
\hline $\begin{array}{c}\text { TEMPOS DE } \\
\text { INCUBAÇÃO }(\mathrm{h})\end{array}$ & \multicolumn{7}{c}{$\begin{array}{c}\text { PORCENTUAL DE DESAPARECIMENTO DA } \\
\text { MATÉRIA SECA (MS) }\end{array}$} \\
\hline \multicolumn{7}{c}{} & \multicolumn{7}{c}{ FCO-40 } & \multicolumn{7}{c}{ FCO-50 } \\
\cline { 2 - 11 } & Caprinos & Bovinos & Média & Caprinos & Bovinos & Média & Caprinos & Bovinos & Média \\
\hline 0 & 9,11 & 8,11 & $8,61 \mathrm{a}$ & 13,92 & 14,45 & $14,19 \mathrm{~b}$ & 31,68 & 31,31 & $31,49 \mathrm{c}$ \\
1,5 & 27,29 & 25,45 & $26,37 \mathrm{a}$ & 27,63 & 25,21 & $26,42 \mathrm{a}$ & 44,67 & 41,69 & $43,18 \mathrm{~b}$ \\
3 & 32,00 & 28,33 & $30,71 \mathrm{a}$ & 31,20 & 27,80 & $29,50 \mathrm{a}$ & 50,74 & 46,69 & $48,72 \mathrm{~b}$ \\
6 & 34,60 & 32,83 & $33,72 \mathrm{a}$ & 36,07 & 33,03 & $34,55 \mathrm{a}$ & 60,63 & 56,37 & $58,50 \mathrm{~b}$ \\
12 & 40,48 & 38,39 & $39,43 \mathrm{a}$ & 40,24 & 37,57 & $28,90 \mathrm{a}$ & 72,22 & 70,28 & $71,25 \mathrm{~b}$ \\
24 & 46,16 & 42,24 & $44,20 \mathrm{a}$ & 44,25 & 472,52 & $43,38 \mathrm{a}$ & 92,52 & 92,09 & $92,31 \mathrm{~b}$ \\
48 & 47,23 & 45,37 & $46,30 \mathrm{a}$ & 49,03 & 46,04 & $47,54 \mathrm{a}$ & 98,05 & 98,03 & $98,04 \mathrm{~b}$ \\
\hline $\mathrm{a}$ & 11,39 & 140,57 & 10,46 & 15,19 & 16,46 & 16,57 & 33,83 & 32,06 & 33,18 \\
$\mathrm{~b}$ & 32,87 & 31,42 & 32,57 & 30,03 & 27,43 & 27,85 & 65,59 & 69,15 & 67,16 \\
$\mathrm{c}$ & 0,28 & 0,25 & 0,28 & 0,22 & 0,14 & 0,17 & 0,08 & 0,07 & 0,07 \\
$(\mathrm{p})$ & 39,40 & 37,70 & 39,00 & 39,90 & 38,10 & 39,10 & 74,60 & 76,50 & 77,40 \\
\hline
\end{tabular}

Letras diferentes, na mesma linha, indicam diferenças significativas $(p<0,05)$ entre médias.

$a=$ fração prontamente solúvel; $b=$ fração potencialmente degradável; $c=$ constante de degradabilidade

\section{DISCUSSÃO E RESULTADOS}

A Tab. I fornece composição química dos alimentos empregados.

As ingestões de MS por animal e por dia foram, para a espécie bovina, iguais a $3,86 \mathrm{~kg}$ de cana e $2,47 \mathrm{~kg}$ de concentrados com um total de $6,33 \mathrm{~kg}(1,8 \mathrm{~kg}$ por $100 \mathrm{~kg}$ de peso ou $78 \mathrm{~g}$ por quilo de peso metabólico). Para a espécie caprina foram iguais a $0,65 \mathrm{~kg}$ de cana-de-açúcar, $0,21 \mathrm{~kg}$ de concentrados com um total de $0,86 \mathrm{~kg}$ $(2.1 \mathrm{~kg} / 10() \mathrm{kg}$ de peso ou $54 \mathrm{~g}$ por quilo de peso metabólico). O consumo registrado foi inferior às estimativas para bovinos ( $\mathrm{NRC}^{17}$. 1989) e equivalente às estimativas para caprinos $\left(\mathrm{NRC}^{16}, 1981\right) . \mathrm{O}$ menor consumo de MS, na espécie bovina, pode ser atribuído ao volumoso utilizado, reconhecidamente de baixa qualidade (canade-açúcar). De acordo com Orskov ${ }^{18}$ (1982), o acréscimo da taxa de passagem, por aumento no nível de consumo, pode causar menor degradabilidade da proteína dietética. Do total de MS ingerida, a mistura de concentrados constituiu $39 \%$ da ração das novilhas e $25 \%$ da ração das cabras. Apesar da relação concentrado/volumoso diferenciada, os resultados não revelam diferenças estatísticas nas

\section{Tabela 3}

Porcentagens de degradabilidade da proteína bruta (PB) da FCO-40, FCO-50 e FS na espécie caprina e na espécie bovina, nos diferentes tempos de incubação ruminal. Degradabilidade efetiva $(p) \operatorname{com} r=0,04$.

\begin{tabular}{|c|c|c|c|c|c|c|c|c|c|}
\hline \multirow[t]{2}{*}{$\begin{array}{l}\text { TEMPOS } \\
\text { INCUBAÇÃ }\end{array}$} & \multicolumn{9}{|c|}{$\begin{array}{c}\text { PORCENTUAL DE DESAPARECIMENTO DA } \\
\text { PROTEINAA BRUTA (PB) }\end{array}$} \\
\hline & \multicolumn{3}{|c|}{ FCO-40 } & \multicolumn{3}{|c|}{ FCO-50 } & \multicolumn{3}{|c|}{ FS } \\
\hline 0 & 17,33 & 14,62 & $15,97 a$ & 17,47 & 16,82 & $17,15 a$ & 18,99 & 16,94 & $17,97 \mathbf{a}$ \\
\hline 1,5 & 43,59 & 40,24 & $41,92 a$ & 29,56 & 30,85 & $30,21 b$ & 33,98 & 26,33 & $30,16 b$ \\
\hline 12 & 57,44 & 55,22 & $56,33 \mathbf{a}$ & 48,96 & 49,45 & $49,21 b$ & 69,61 & 58,59 & $64,10 \mathrm{c}$ \\
\hline 24 & 60,41 & 58,98 & $59,70 \mathbf{a}$ & 54,51 & 56,38 & $55,44 a$ & 92,61 & 90,43 & $91,52 b$ \\
\hline 48 & 62,70 & 60,71 & $61,70 \mathrm{a}$ & 59,44 & 62,03 & $60,73 a$ & 99,25 & 99,43 & $99,34 b$ \\
\hline$a$ & 18,10 & 14,64 & 15,96 & 18,67 & 18,72 & 19,07 & 20,70 & 16,30 & 18,85 \\
\hline$b$ & 40,16 & 42,16 & 41,55 & 37,42 & 39,97 & 38,01 & 79,74 & 90,80 & 84,51 \\
\hline
\end{tabular}

Letras diferentes, na mesma linha, indicam diferenças significativas $(p<0,05)$ entre médias.

$a=$ fração prontamente solúvel; $b=$ fração potencialmente degradável; $c=$ constante de degradabilidade. 
degradabilidades efetivas da MS e PB entre espécies. Segundo Vilela et $a l .{ }^{27}$ ( 1994$)$, a relação concentrado:volumoso não exerceria maior influência sobre a degradabilidade da FCO e FS.

As taxas de desaparecimento de MS e das FCO-40, FCO-50 e do FS foram semelhantes entre caprinos e bovinos. A Tab. 2 dá os resultados para ambas as espécies, bem como os resultados da aplicação da equação de regressão de Orskov; McDonald ${ }^{\prime \prime}$ (1979), $(p=a+b(1-e-c t)$, para obter as constantes "a", "b" e "c" e a degradabilidade efetiva ( $p$ ) da MS, segundo a fórmula de AFRC' (1992), $p=a+b c / c+r$

As FCO-40 e FCO-50 tiveram comportamento semelhante. ambas apresentando menor degradabilidade $(p<0,01)$ que o FS, nos tempos de incubação 1,5 h, 3 h, 6 h, 12 h, 24 h e 48 h. Apesar de os caprinos apresentarem maiores valores de degradabilidade na MS da FCO-40 e FCO-50 e menores para o FS, em relação aos bovinos, os resultados foram considerados estatisticamente semelhantes.

A degradabilidade efetiva (p) da MS foi de $77,4 \%$ para FS, $39,0 \%$ para $\mathrm{FCO}-40$ e $39,1 \%$ para FCO-50, ou seja, quase o dobro (198\%) para o FS, considerando-se $r=0,04$. Esta degradabilidade efetiva da MS, revelada para o FS $(77,4 \%)$, foi superior aos dados obtidos por Kirpatrick; Kennely ${ }^{12}$ (1987), com 66,6\% a $69,4 \%$ $(r=0,05)$, Valadares Filho et al. ${ }^{25}(1990)$, com 71,8\% e $(r=0,05)$, Vilela et al. ${ }^{27}$ (1994), com 74,8\% a 77,2\% $(r=0,02$ a 0,05$)$. Já para as $\mathrm{FCO}$, os resultados da degradabilidade efetiva das matérias secas $(39,0 \%$ para FCO-40 e 39, $\%$ para a FCO-50 com r =0,04) tiveram valores similares aos encontrados por Kirpatrick; Kennely ${ }^{12}$ (1987), com $39,0 \%(r=0,05)$, revelando maior resistência ao ataque microbiano no rúmen do que o farelo de soja.

A Tab. 3 mostra resultados de degradabilidade da PB obtidos isoladamente para cada uma das espécies, bem como os dados resultantes da aplicação da equação de Orskov; McDonald ${ }^{19}$ (1979), e degradabilidade efetiva segundo o $\mathrm{AFRC}^{\rfloor}$(1992).

As taxas de degradabilidade da PB foram semelhantes entre caprinos e bovinos. Nos tempos de $1,5 \mathrm{~h}, 3 \mathrm{~h}, 6 \mathrm{~h}$ e $12 \mathrm{~h}$ a FCO-50 teve a proteína menos degradada que a FCO-40. O FS teve a PB mais degradada do que a FCO-40 e 50 somente nos tempos de 12 h, 24 h e 48 h de incubação $(p<0,05)$. Isto signi- fica que até as $6 \mathrm{~h}$, as taxas de degradação foram semelhantes ou até menores para o FS, e só após 12 horas de incubação a proteína do FS apresentou uma degradabilidade maior do que as FCO Assim, em altas porções de concentrados na dieta e para níveis elevados de produção, com taxas de efluente ruminal próximas a $10 \%(r=0,1)$, as vantagens em fornecer FCO deverão ser menores que o normalmente esperado em termos de degradabilidade. Este resultado é de importância prática já que, no caso das vacas de leite, fontes de proteína não degradáveis são utilizadas apenas em rebanhos de elevada produção. Evidentemente, a fração proteica não degradada da FCO será de melhor valor que a parte não degradada do farelo de soja, em termos de eficiência de utilização.

A degradabilidade efetiva da PB da FS $(72,40 \%)$ revelou-se superior aos valores obtidos pelo $\mathrm{ARC}^{2}(1980)$, com $51 \%$ a $70 \%$, $\operatorname{NCR}^{17}$ (1989), com 65\%, Vogel et al. ${ }^{28}$ (1988), com 62,5\%, Goh; Hong $^{8}$ (1983), com 44,0\% a 52,9\%, Kirpatrick; Kennely ${ }^{12}$ (1987), com 60,2\% a 64,4\%, Loerch el al. ${ }^{13}$ (1983b) com 71,3\%. Broderick et al. ${ }^{4}$ (1988), com 63\%, Valadares Filho et al. ${ }^{25}(1990)$, com 66,6\%, e inferior aos encontrados por Goh; Hong ${ }^{\aleph}$ (1983), com 75,77\%, Zinn el al. ${ }^{29}(1981)$, com 82\%, Vilela el al. ${ }^{27}$ (1994), com 78,4\% a $85,7 \%$. A discrepância dos dados pode ser atribuída ao fato de os farelos possuírem níveis proteicos desiguais, às diferentes temperaturas de aplicação dos tratamentos e aos erros inerentes à técnica dos sacos in situ.

A degradabilidade efetiva média da PB das FCO $(52,1 \%)$ revelou-se superior aos dados obtidos por Kirpatrick; Kennely ${ }^{2}$ (1987), com 45,9\%, Zinn et al. ${ }^{29}$ (1981), com 30\%, Vogel et al..$^{28}$ (1988), com 44\%, Valadares Filho et al. ${ }^{25}(1990)$, com $34 \%$ a $41 \%$, Loerch et al. ${ }^{13}$ (1983b), com 50,7\%, e $\mathrm{NRC}^{17}$ (1989), com 51\%, $\mathrm{ARC}^{2}(1980)$, com $31 \%$ a $50 \%$, e inferior ao obtido por Broderick et $a .^{4}{ }^{4}(1988), \operatorname{com} 55 \%$. As mesmas considerações relativas à alta variação dos dados do farelo de soja também cabem aqui.

A Tab. 4 contém os resultados de degradabilidade efetiva da PB das FCO e FS, através da aplicação da fórmula proposta pelo AFRC $^{\prime}$ (1992) para diferentes taxas de passagem.

Os resultados demonstraram uma diminuição da degradabilidade com o aumento da taxa de passagem, principalmente para FS, bem como valores muito próximos para a FCO-40 e FCO-50. O farelo de soja tem sua degradabilidade ruminal muito mais sensível à variação da taxa de passagem pelo proventrículo que a FCO; a mudança da taxa de passagem (r) de 0,02 para $0,08 \mathrm{~h}$ imprimiu ao FS redução de $31,3 \%$ na degradabilidade efetiva da $\mathrm{PB}$; no caso da FCO-40, a redução foi de 7,3\%, e na FCO-50, foi $15,5 \%$. As degradabilidades efetivas encontradas na Tab. 4 confirmaram a tendência de outros trabalhos, embora revelando-se inferiores às obtidas para o FS por Broderick et al. ${ }^{4}$ (1988) e superiores às obtidas por Orskov ${ }^{18}$ (1982) e às obtidas para as FCO por Orskov et al. ${ }^{19}(1979)$.

Tabela 4

Degradabilidade efetiva da proteína bruta e de matéria seca, estimada sob diferentes taxas de passagem, para caprinos e bovinos, em média.

\begin{tabular}{|c|c|c|c|c|c|c|c|c|}
\hline \multicolumn{2}{|c|}{ TRATAMENTOS } & \multicolumn{6}{|c|}{$\begin{array}{c}\text { DEGRADABILIDADE DA PROTEÍNA BRUTA (\%) } \\
\text { TAXA DE PASSAGEM / } h(r)\end{array}$} & \multirow[b]{2}{*}{0,08} \\
\hline & & 0,02 & 0,03 & 0,04 & 0,05 & 0,06 & 0,07 & \\
\hline Proteína & Farinha de carne e osso 40 & 55,9 & 55,2 & 54,4 & 53,7 & 53,1 & 52,4 & 51,8 \\
\hline \multirow[t]{2}{*}{ Bruta } & Farinha de carne e osso 50 & 53,1 & 51,4 & 49,8 & 48,4 & 47,1 & 46,0 & 44,9 \\
\hline & Farelo de soja & 84,4 & 77,8 & 72,4 & 67,9 & 64,1 & 60,8 & 58,0 \\
\hline Matéria & Farinha de carne e osso 40 & 40,9 & 39,9 & 39,0 & 38,1 & 37,3 & 36,5 & 35,8 \\
\hline \multirow[t]{2}{*}{ Seca } & Farinha de carne e osso 50 & 50,5 & 40,3 & 39,1 & 38,1 & 37,2 & 36,3 & 35,5 \\
\hline & Farelo de soja & 86,5 & 81,5 & 77,4 & 73,9 & 70,9 & 68,4 & 66,1 \\
\hline
\end{tabular}


Os valores de turn over obtidos pelo emprego do PEG foram iguais a 1,59 (caprinos) e 3,39 (bovinos) por 24 horas; os volumes ruminais foram 6,6 litros (caprinos) e 34,5 litros (bovinos). As taxas de passagem por hora foram 0,05 e 0,04 para caprinos e bovinos respectivamente. Estes resultados superaram os encontrados por Thomas et $a l .^{24}(1988)$, mas foram semelhantes nas espécies caprina e bovina. Os valores registrados $(0,04 / \mathrm{h}$ para bovinos ou 0,05/h para caprinos) provavelmente não devem ter influído sobre os desaparecimentos da MS e PB.

\section{CONCLUSÕES}

Para as condições do presente experimento, foi possível enumerar as seguintes conclusões:

1) Não ocorreram problemas de palatabilidade com o uso de quaisquer das fontes proteicas, a julgar pela ingestão de MS do concentrado;

2) Para a MS, as FCO apresentaram, em todos os tempos de incubação, menores taxas de desaparecimento da MS do que o FS (p 0,01);

3) Para a PB, o FS comparou-se à da FCO $50 \%$ até as $6 \mathrm{~h}$ de incubação, e só a partir de $12 \mathrm{~h}$ a degradabilidade proteica do FS passou a ser maior que das FCO;

4) A FCO $50 \%$ de PB apresentou menores taxas de degradabilidade proteica entre $1,5 \mathrm{~h}$ e $12 \mathrm{~h}$ de incubação do que a FCO $40 \%$;

5) As espécies caprina e bovina não mostraram diferenças na utilização da MS e PB das fontes proteicas estudadas; FCO-40, FCO-50 e FS apresentaram, respectivamente, valores médios de $39 \%, 39,1 \%$ e $77,4 \%$ (MS); $54,4 \%, 49,8 \%$ e $72,4 \%$ (PB), considerando taxa de passagem (r) igual a $0,04 / \mathrm{h}$.

\section{SUMMARY}

Goats and heifers were used in a $3 \times 3$ change over design to evaluate the treatments: A) Meat and bone meal with $50 \%$ of CP (MBM 50), B) Meat and bone meal with $40 \%$ of CP (MBM 40), C) Soybean meal (SM). In situ nylon bag technique was used. Sugar cane was fed as the only roughage. Rates of disappearance of DM and CP were similar for goats and bovines in all treatments. DM of MBM 40 and MBM 50 presented similar degradability rates, and both had minor degradability ( $p<0.01$ ) than SM beginning at $1.5 \mathrm{~h}$ incubation time. Effective degradability of DM was $77.4 \%$ (SM), 39.0\% (MBM 40) and $39.0 \%$ (MBM 50). At incubation times $1.5 \mathrm{~h}, 3 \mathrm{~h}, 6 \mathrm{~h}$ and $12 \mathrm{~h}, \mathrm{MBM} 50$ had less protein degraded than MBM 40. SM had CP more degraded than MBM only at $12 \mathrm{~h}, 24 \mathrm{~h}$ and $48 \mathrm{~h}$ of incubation time $(\mathrm{p}<0.05)$. Effective degradability of CP was $72.4 \%$ (SM), $54.4 \%$ (MBM 40) and 49,8\% (MBM 50). It was concluded that both meat and bone meals can provide more undegraded protein, related to soybean meal, after 12 hours of incubation time.

\section{UNITERMS: Digestibility; Caprines; Bovines; Soybean meal; Meatand bone neal.}

\section{RES̄ERÊNCIAS BIBLIOGRÁFICAS}

I - AFRC - AGRICUITURAL, AND FOOD RESEARCH COUNCIL. Nutritive Requirements of Ruminant Animal: protein. Nutrition Abstracts and Reviews, Series B, v.62, n. 12, p.787-835, 1992

2 - ARC - ACiRICULTURAL, RESEARCH COUNCIL. The Nutrient Requirement of Ruminant Iivestock. Commonwealth Agricultural Bureaux, Farnham Royal, 1980. 35Ip.

3- AOAC - ASSOCIATION OF OFFICIAL AGRICULTURAL CHEMISTS Official methods of analysis. I0 ed. Washington, 1980. p. II4I

4 - BROIDERICK, G.A.; WALLACE, R.J.; ORSKOV, E.R.; HANSEN, L. Comparison of estimates of ruminal protein degradation by in vitro and in situ methods. Journal of Animal Science, v.66, n.7, p. 1739-45, 1988.

5 - CNPSA - CENTRO NACIONAL DE PESQUISA DE SUÍNOS E AVES. Tabela de composição química e valores energéticos de alimentos para suínos e aves. 3 ed., Concórdia, Einbrapa, 1985. 97 p.

6 - COCHRAN. W.G.; COX, G.M. Experimental design. New York, John Wiley e Sons, 1957.61I p

7 - DONZELE, J.L.; LOPES, D.C. Valor nutritivo da farinha de carne e osso para suínos. Informe Agropecuário, v.13, n. 156, p.66-71, 1988.

8 - GOH, Y.G.; HONG, B.J. Effect of heat and formaldehyde treatment on the protein degradability of soybean meal by in situ method. Nutrition Abstracts and Reviews, Series B, v.63, n. I, p. 14, 1993.

9 - GOMES, F.P. Curso de estatística experimental. 13 ed. Piracicaba,SP, Nobel. 1990. p. 5.
10 - HYDEN, S. A turbodometric method for the determination of higher polyethylene glucols in biological material. Lantbr. Hogst Ann., v.22, n. 22, p. $139-45$ 1986.

Il - JUST, A.; FERNANDEZ, J.A.; JORGENSEN, H. The value of meat and bone meal for pigs. Nutrition Abstracts Reviews, Série B, v.53, n.8, p.524, 1983

I2 - KIRKPATRICK, B.K.; KENNELLY.J.J. In situ degradability of protein and dry matter from single protein sources and from a total diet. Journal of Animal Science, v.65, n.2, p.567-76. 1987.

13 - LOERCH, S.C.; BERGER, L.L.; PI.EGGE, S.D.; FAHEY JR., G.C. Digestibility and rumen escape of soybean meal, blood meal, meal and bone meal and dehydrated alfafa nitrogen. Journal of Animal Science, v.57, n.4, p. 1037 $1047,1983 \mathrm{~b}$

14 - LU, C.D.; POTCHOIBA, M.J.; SAHLU, T.; KAWAS, J.R. Performance of dairy goats fed soybean meal or meal and bone meal with or without urea during early lactation. Journal of Dairy Science. v.73, n. 3, p.726-34, 1990.

I5 - LU, C.D.; POTCHOIBA, M.J.; SAHLUT, T. Integration of meat and bone meal and urea in lactation rations for dairy goats. Journal of Dairy Science, v. 71 p.159, 1988, Supplement 1 .

16 - NATIONAL RESEARCH COUNCIL. Nutrient requirements of goats. Washington, National Academy Press, $1981.91 \mathrm{p}$

17 - NATIONAL RESEARCH COUNCIL. Nutrient requirements of dairy cattle Washington, National Academy Press, 1989. $169^{\circ} \mathrm{p}$.

18 - ORSKOV, E.R. Protein nutrition in ruminants. London, Academic Press 1982. 160 p 
19 - ORSKOV, E.R.; McDONALD, I. The estimation of protein degradability in the rumen from incubation measurements weighed according to rate of passage. Journal of Agricultural Science, v.92, n.2, p.499-503, 1979.

20 - PIECZNSKI, R.; NIERODZIK, A.; HARENZA, T. Nutritive value of meat and bone meal estimaled by the Hartinann method. Nutrition Abstracts and Reviews, Série B, v.56, n.8, p.495, 1986.

2 I - ROOKE, J.A. The nutritive values of feed proteins and feed protein residues resistant to degradation by rumen microorganisms. Journal of the Science of Food and Agriculture, v.36, n.8, p.629-37, 1985

22 - SCOTT, L.M.; NEISHEIM, M.C.; YONG, R.J. Nutrition of the chicken. Itaca, M.L. Scoll e Associates, 1982. 562p.

23 - SECRETARIA NACIONAL DE DEFESA AGROPECUÁRIA. Padrões mínimos de diversas matérias-primas utilizadas na alimentação animal. Diário Oficial da União, 21 nov. 1988

24 - THOMAS, E.E.; TURNBULL, G.W.; RUSSEL, R.W. Effect of particle size and steam treatment of feedstuffs on rate and extent of digestion (in vitro and in situ). Journal of Animal Science, v.66, n.1, p.243-9, 1988.
25 - VALADARES FILHO, S.C.; SILVA, J.F.C.; LEĀO, M.I.; EUCLIDES, R. F.; VALADARES, R.F.D.; CASTRO, A.C.G. Degradabilidade "in situ"da matéria seca e proteína bruta de vários alimentos em vacas em lactação. Revista da Sociedade Brasileira de Zootecnia, v. 19, n.6, p.5I2-22, 1990.

26 - VALLE, R.P. Valor nutritivo das farinhas de carne e osso bovino e eqüina avaliada por métodos químicos e biológicos. Bclo Horizonte. 1975. 63p. Dissertação (Mestrado). Faculdade de Medicina Veterinária, Universidade Federal de Minas Gerais.

27 - VILELA, G.L.; VALADARES FILHO, S.C.; SILVA. J.F.C.; CECON, P. R.; PEREIRA, J.C.; ALMEIDA, R.G. Efeitos de diferentes rações nas degradabilidades "in situ"potenciais da matéria seca e da proteína bruta de vários alimentos. Revista da Sociedade Brasileira de Zootecnia, v.23, n.3, p.333-4I, 1994

28 - VOGEL, G. J.; ANDERSEN, M.A.; HORN, G.W. Ruminal degradability of protein supplements by stocker cattle grazing wheat pasture. Animal Science Research Report, n. MP-125, p.117-21, 1988

29 - ZINN, R.A.; BULL, L.S.: HEMKEN, R.W. Degradation of supplemental proteins in the rumen. Journal of Animal Science, v.52, n.4, p.857-866, 1981. 